احتمابات هونه كونه

\title{
دوافع هتمددة وخيارات همدودة
}

هقدهمة

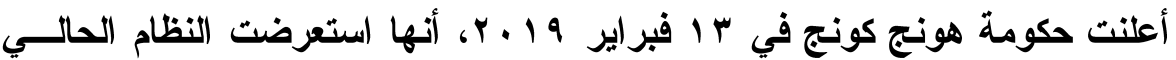

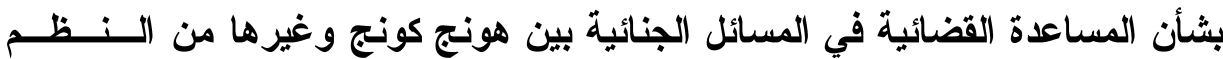
القضائية، وأنها تفكر في تعديل قانون المساعدة القانونية المتبادلة في المسائل الجنائية وقانون الجناة الهاربين (الفصل ب ـ0)، نظراً لوجود ثغرات في النظام الحالي الخــاص بتسليم المشتبه بهم في القضايا الجنائية إلى ولايات قضائية أخرى (1).

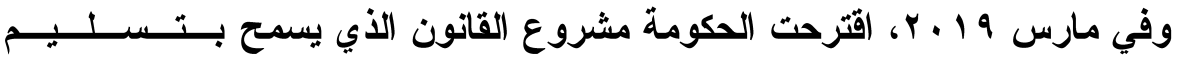

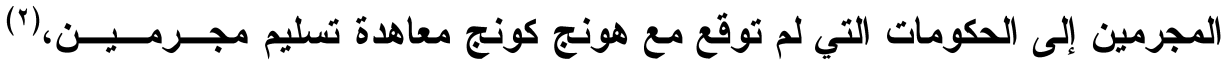

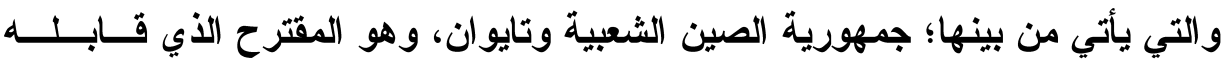
انتقاد وتحذيرات واسعة من مختلف فئات المجتمع و القطاعات و الكيانات في المقاطعـة

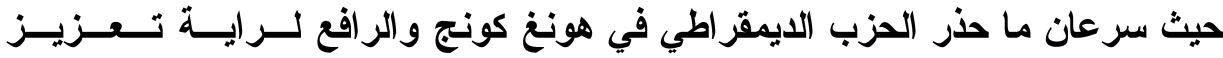

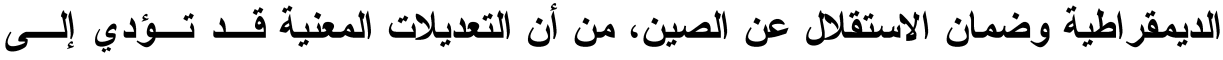

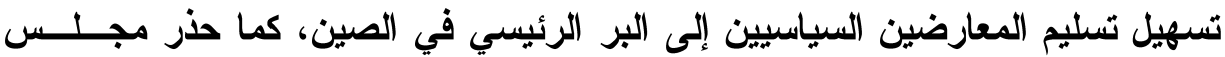

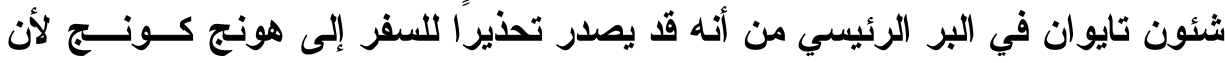

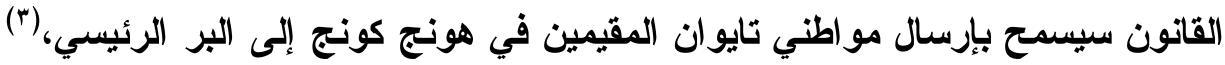

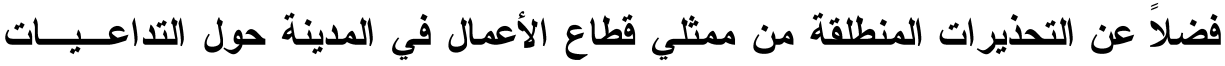
الخطرة لهذا المشروع على قطاع الأعمال و الاقتصاد في المدينة. 


\section{6}

بالإضافة إلى ما سبق، قام اعضاء القطاع القانوني بتنظيم مسيرة سلميــة فــي 7 يونيو انطلقت من محكمة الاستئناف النهائية إلى مكاتب الحكومة المركزية، احتجاجـاً

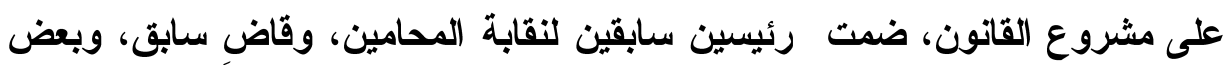
المدعين العامين من وزارة العدل، وبلغ عدد المشاركين في المسيرة نحو ثـلاث آلاف

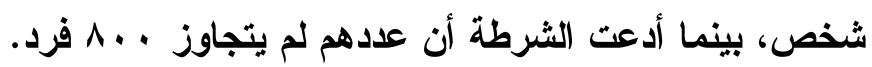
وعلى الرغم من حالة القلق والمخاوف المتصاعدة من قبل شريحة واســــة مــن المجتمع تجاه مشروع القانون، عززتها التحذيرات المتنوعة من تداعــــــات إقــراره،

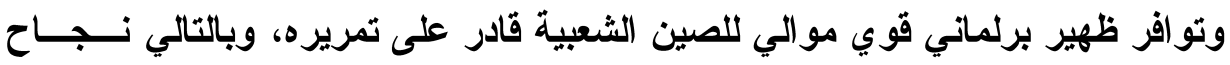
حكومة هونج كونج في اسكات القوى الر افضة بالطرق السلمية، إلا أن حكومة المدينة تجاهلت تللك المخاوف أو بالمعني الأدق لم تضعها في نصابها وأعلنت عن المضي قدماً لخضوع مشروع القانون لقراعة ثانية يوم r ا يونيو في المجلس التشريعي،(ء) وهو ما عكس جانبا كبيرا من الفجوة وانعدام الثقة بين مواطني هونج كــونــج ومشـرعــي ومسئولي المدينة، وتأكيا منظور قطاع واسع من المجتمع بأنهم بمثابة امتداد لسياسات الصين الشعبية وممثلين للحزب الشيوعي الصيني في هونج كونج. نتيجة لما سبق، اتسعت دائرة الاحتجاجات منذ اندلاعها في مارس بحوالي . . . . .

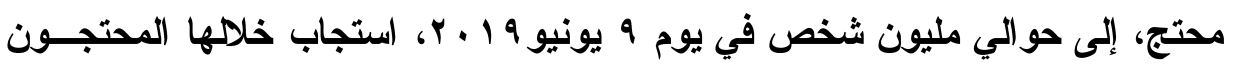
إلى دعوة الحزب الايمقراطي في المدينة بالاحتشاد حول مبنى المجلس التشريعي لدفع

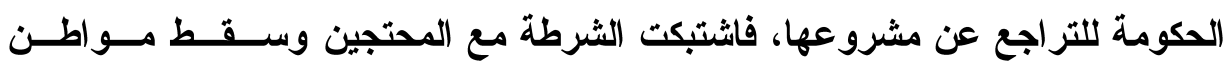

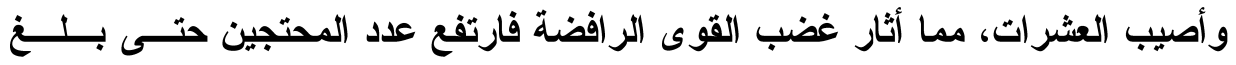

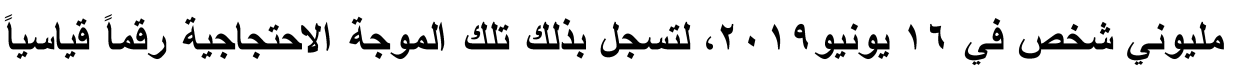

في تاريخ المدينة منذ عودتها للحكم الصيني عام 99 ل 19 (०). وفي شهر أغسطس، شهرت الاحتجاجات منعطفاً جديداً تمثل في تحول المحتجــــن من استهاف الهيئات والمباني الحكومية بما في ذلك المكتب الذي يمثل الصيـن فـي 


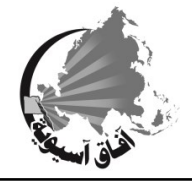

المدينة، لاعوة المحتجين لتنظيم اضراب عام تعطلت على إثره حركة النقــل الــــــام،

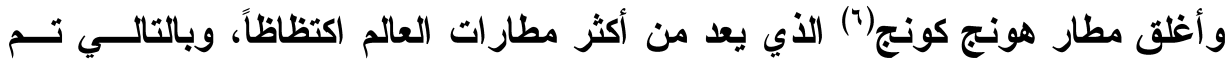
إلغاء كافة رحلاته الجوية، وفي ظل تصاعد حالة الكر والفر بين المحتجـــــن وقــوات الشرطة، تمكنت القوات الأمنية من اعتقال أكثر من . . . 1 شخص حتى سبتـــــــر (الماضي.) (v)

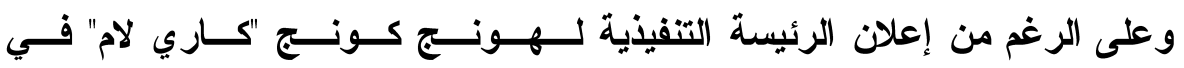

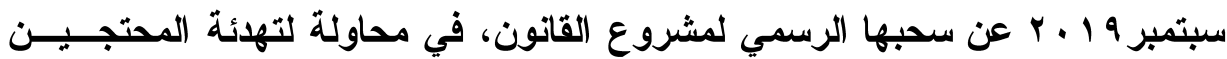
والتعبير عن حرص الحكومة لفتح حوار معهم والبحث عن مخرج لتلك الأزمة، إلا أن

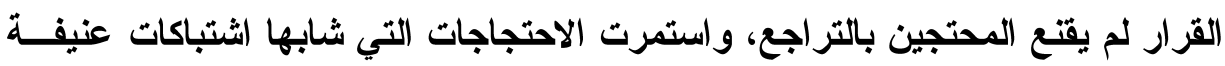
بين الجانبين، وهو ما يدفع للتشاؤل عن الادفع وراء استمرار تلك الاحتجاجات عــــى

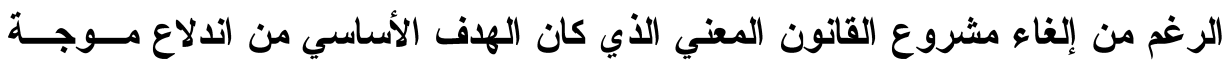
احتجاجات هونج كونج في هذا العام 9 1 ـ ب.

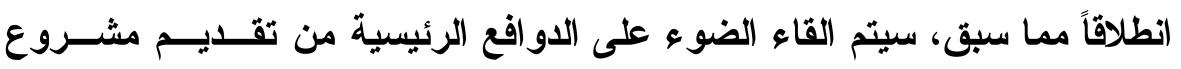

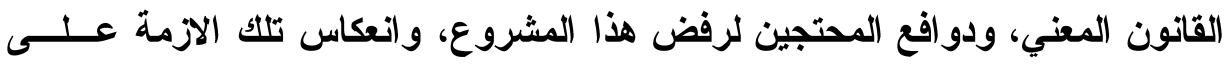
الوضع الاقتصادى لهونج كونج، وتحليل الخيارات المحدودة والمتاحة لإنهاء الأزمة.

\section{أولاً: دوافع اندلاع احتجاجات هونج كونج.. ها بين المعلن والففي}

أعلنت زعيمة هونج كونج "كاري لام" في أكثر من تصريح لها أن الهدف الأساســي

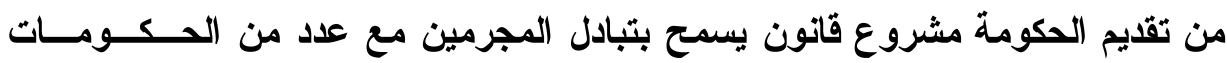

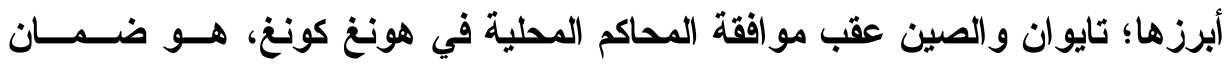

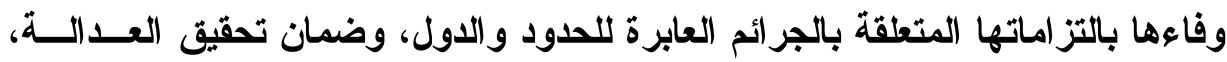

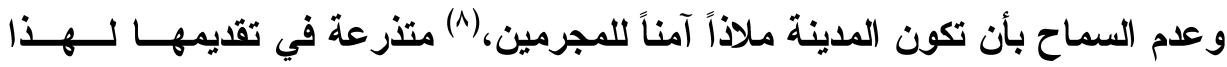
المشروع بقضية "تثان"، التي رفضت المدينة طلبات السلطة التايوانية الثلاث بتسليمه

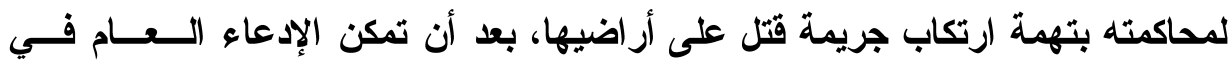





\section{6}

ثالثها؛ إضفاء الشرعية على عمليات الاختطاف التى تمارسها بكين في هونج كونج ضد عدد من المطلوبين من الحكومة الصينية يعود غالبيتها لقضايا سياسية، وهو مـــا

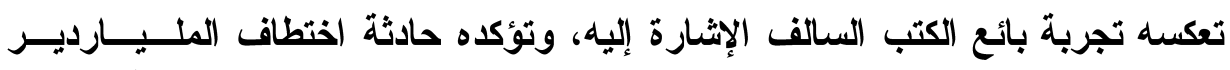

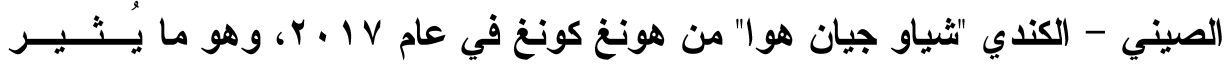

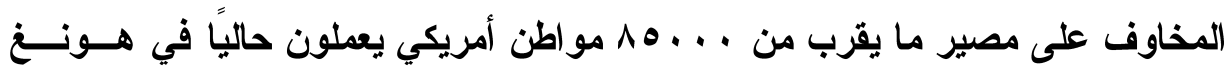

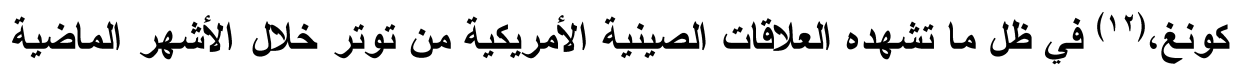
جر اء "الحرب التجارية" بينهما. ويبدو أن حكومة تايوان قد أدركت المقصد من تقديم حكومة هونج كونج مشــروع القانون المعني، فاعلنت في مايو 9 ـ ب أنها لن تسير قُدماً في طلب تسليمها "تثان"، حتى لو تم اعتماد التشريع الأي تقدمت به هونج كونج، نظراً لعدم تبديد مخاوفها بشأن

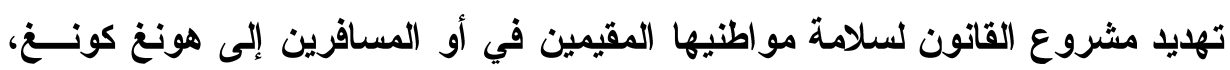

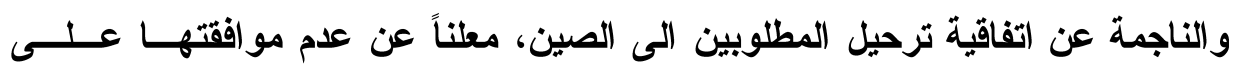

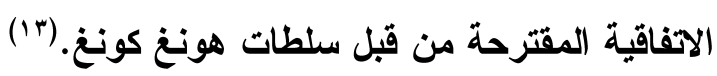

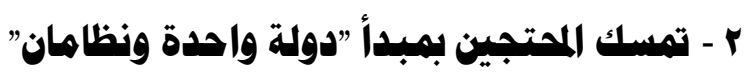
هناك دافعان رئيسيان لاندلاع الموجة الاحتجاجية الواسعة التي تثهرها المدينة منذ

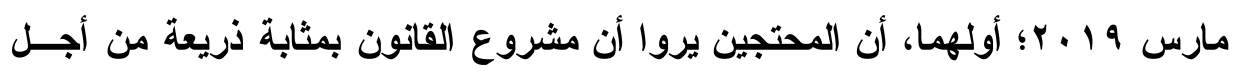
استهداف الصحفيين والناشطيين السياسيين المعارضين لحكومة بكين ولحكومتهم بمسـا

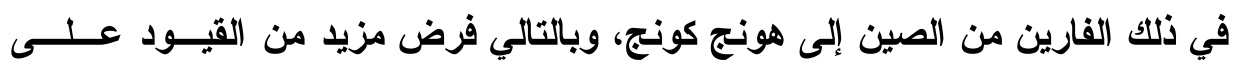

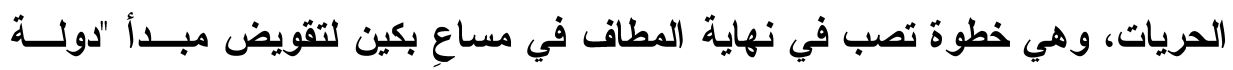

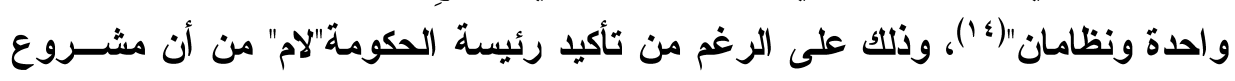

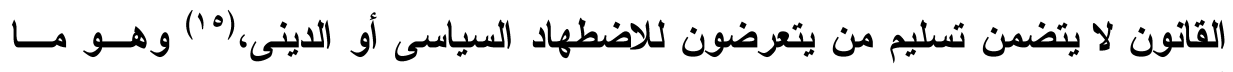

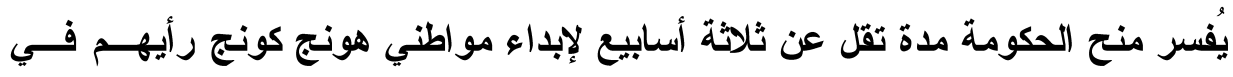

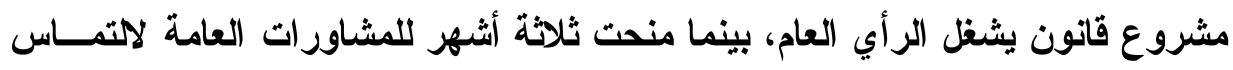

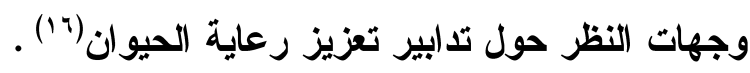




\section{6.}

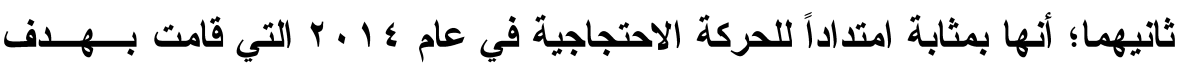

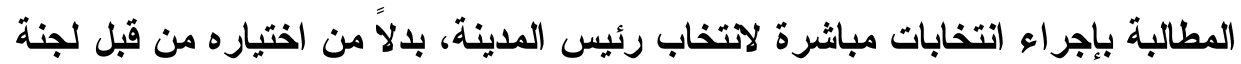

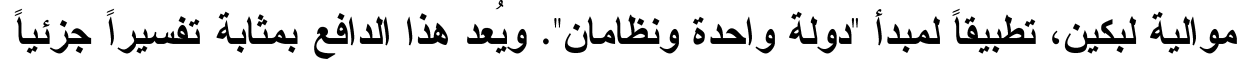

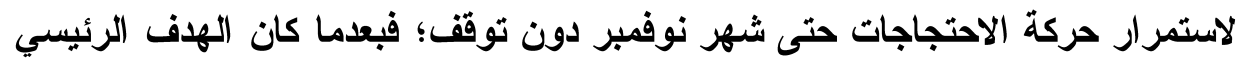

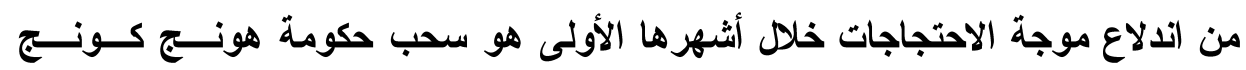

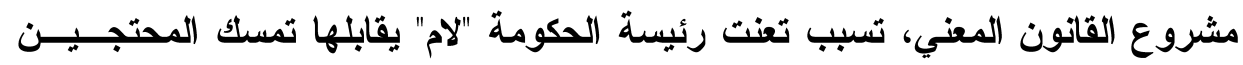

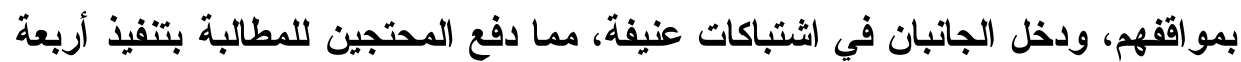

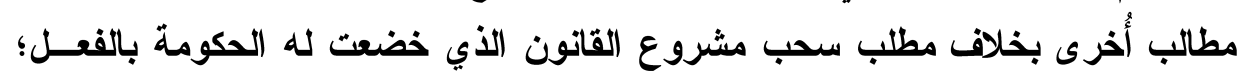

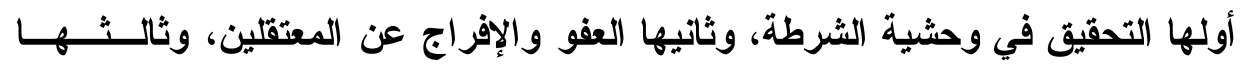

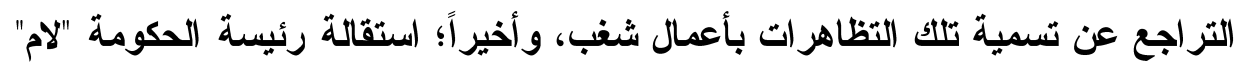
و إجراء انتخابات حرة ونزيهة لاتخاب من يخلفها (1') .

\section{ثانيًا: انعكاسات الحركة الاحتجاجية على اقتصاد هونج كونج}

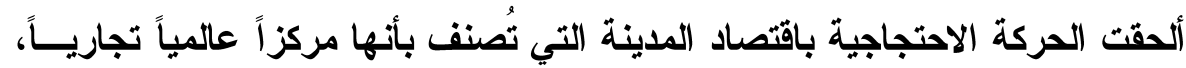

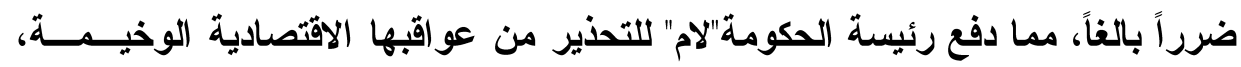

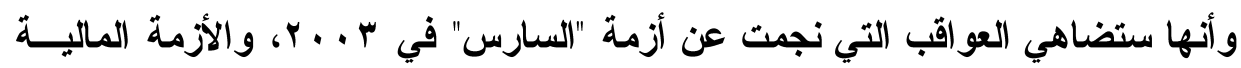

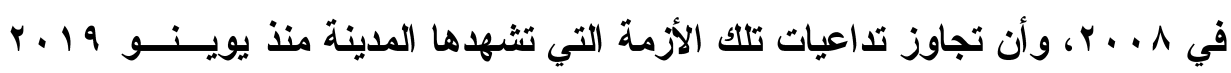
سيستغرق وقتاً طويلاًُ (^).

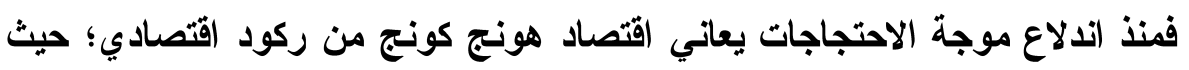

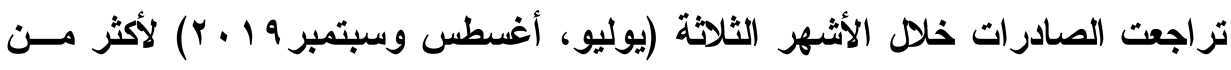

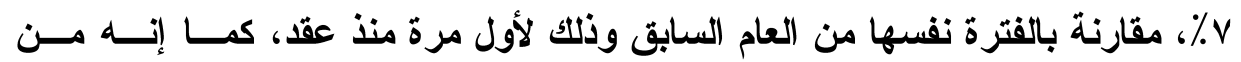

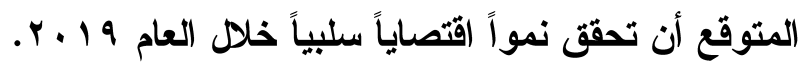

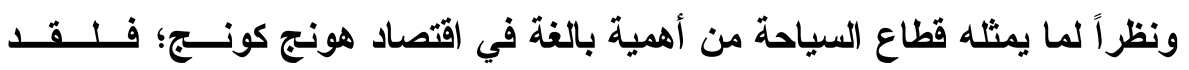

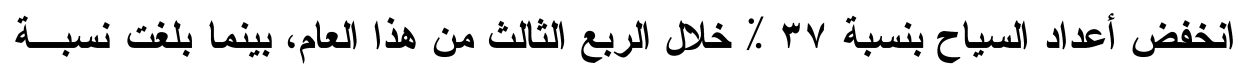




\section{敦}

انخفاض عدد السياح خلال النصف الأول من شهر أكتوبر ، ه \% مقارنة بذات الفترة من

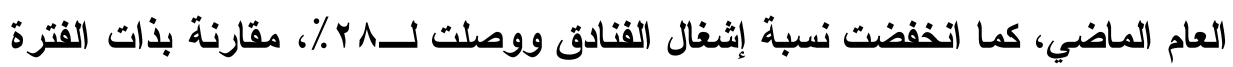

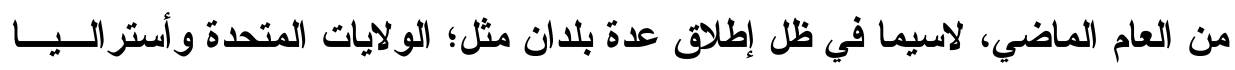

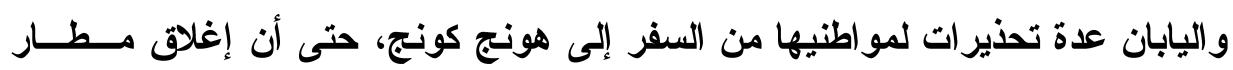

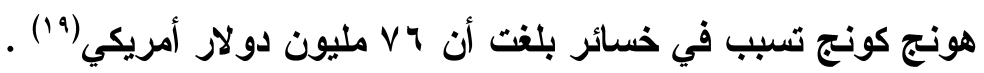
كما كان لتراجع قطاع السياحة تأثيراً على كافة اقتصاد المدينة من مطاعم ومحلات وغيرها من خدمات مقدمة، فعلى سبيل المثال أُجبرت عدة متاجر على الإغلاق مبكــاً

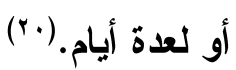

ولقد لجأت رئيسة حكومة هونج كونج لاتخاذ عدة سياسات اقتصادية لاعم الثركات

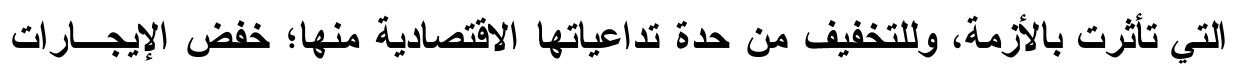

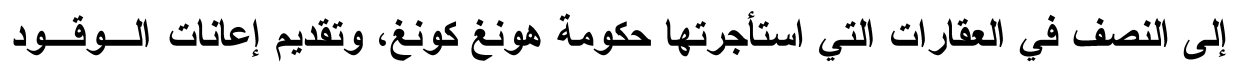

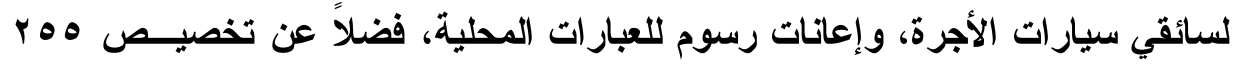

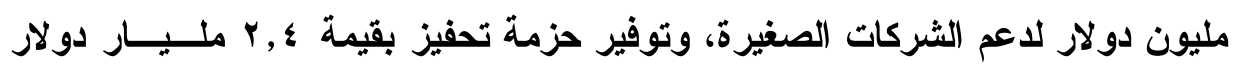

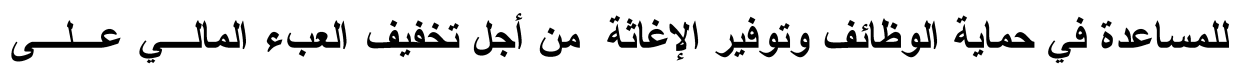

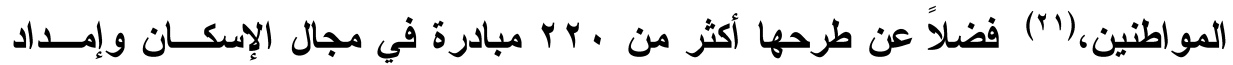

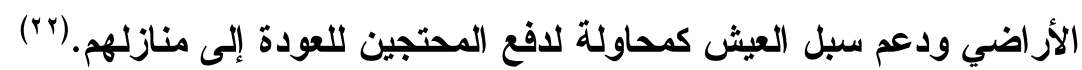
لكن في ذات الوقت، حافظت الأسواق المالية على تميزها وتفردها وهو ما يعكـس المس

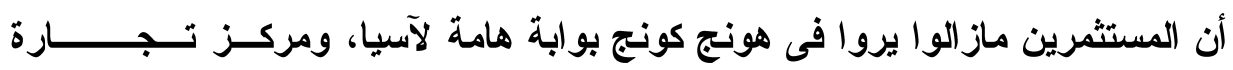

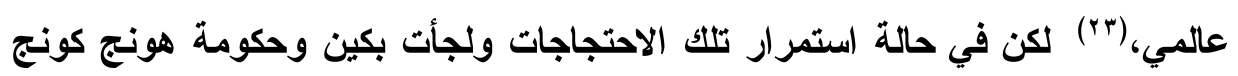

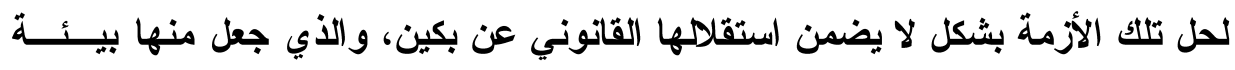

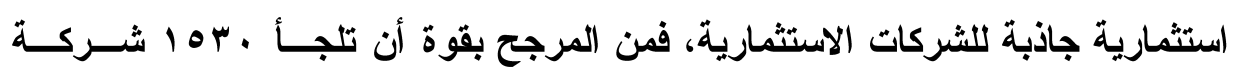
متعددة الجنسيات اتخذت من هونج كونج موطئ قدم لفتح مقرات إقليمية لها في عـام

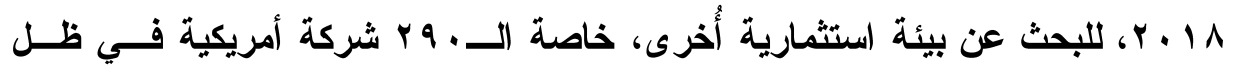
الحرب التجارية الصينية الأمريكية. 


\section{6}

\section{ثالثًا: هستقبل احتجاجات هونج كونج .. خيارات هدودة}

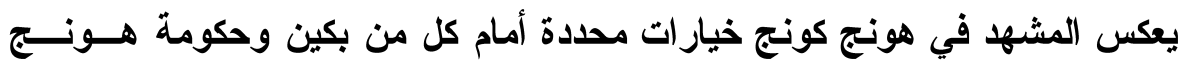

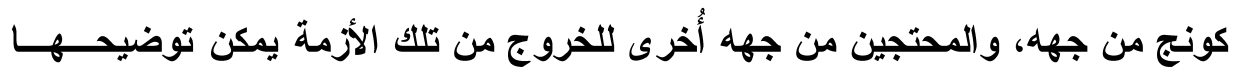

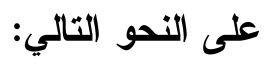

1- تدخل القوات الصينية لحمابة النظام العام في هونج كونج

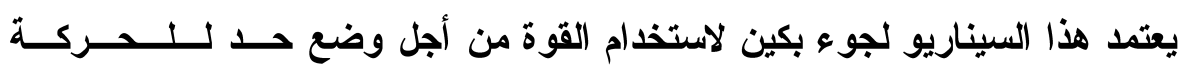

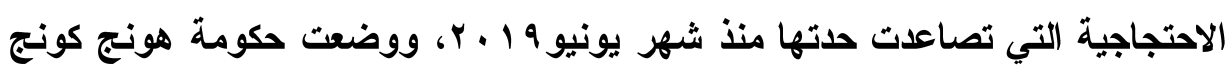

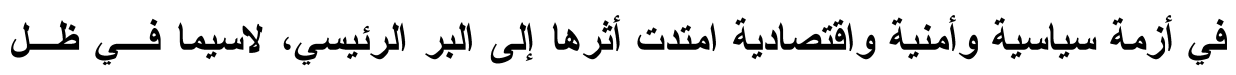

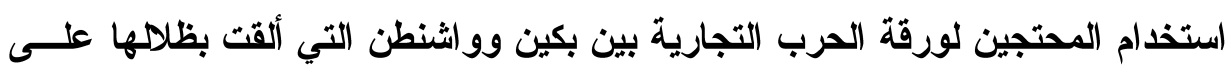

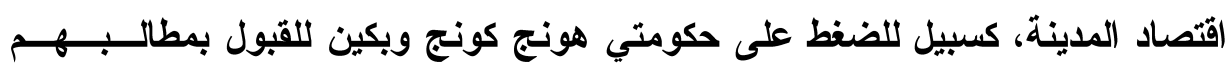

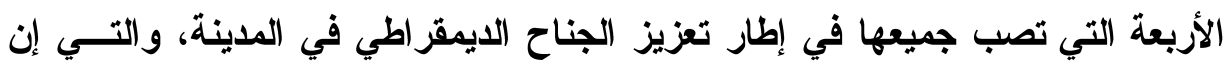

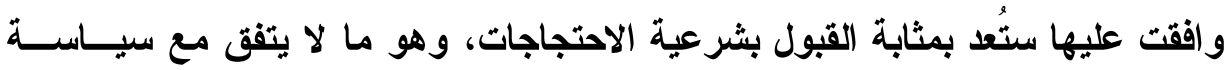

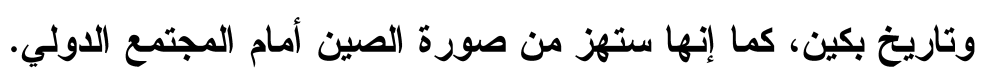

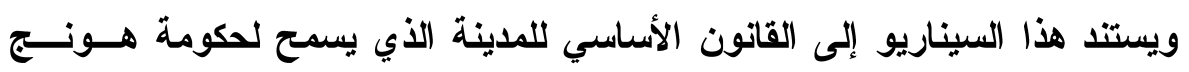

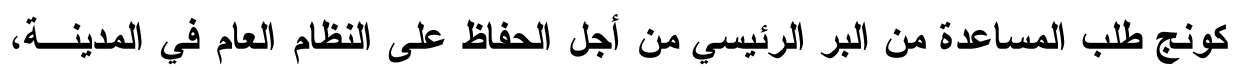

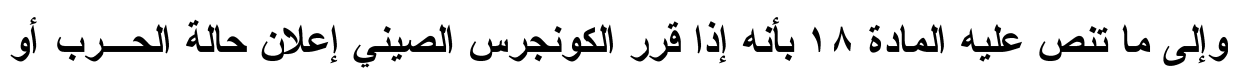

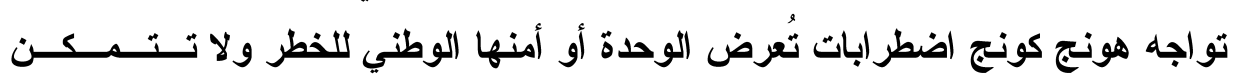

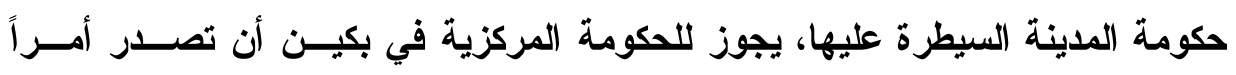
بتطبيق القوانين الوطنية ذات الصلة في المدينة.

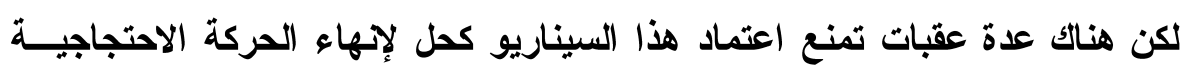

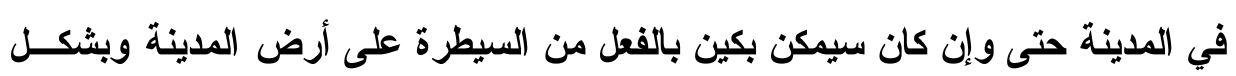

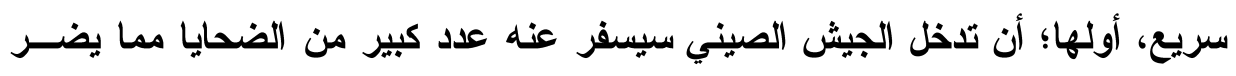

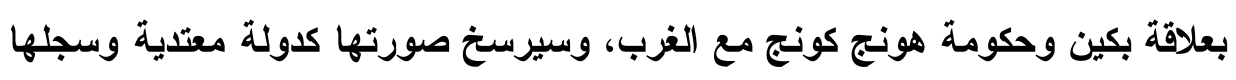




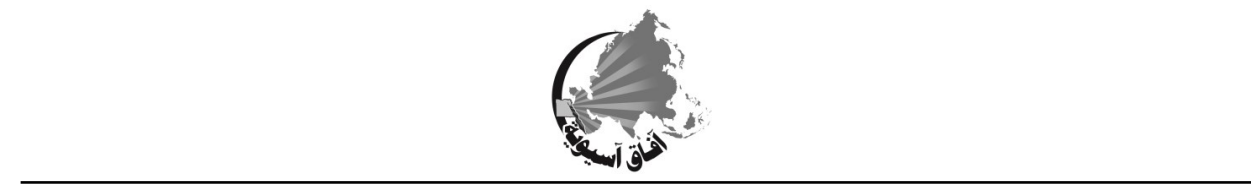

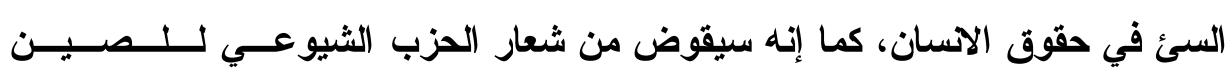

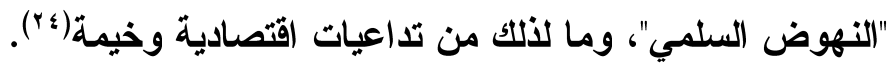
ثان تلأك العقبات يتمثل فى أن واثنطن ستستغل هذا الأمر لشرعنة حربها التجاريــة

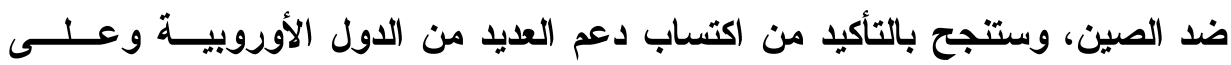
رأسها؛ بريطانيا-المستعمر السابق لهونج كونج-والتي ستتأثز علاقتها الاقتصــاديــة

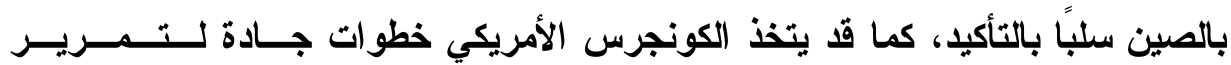

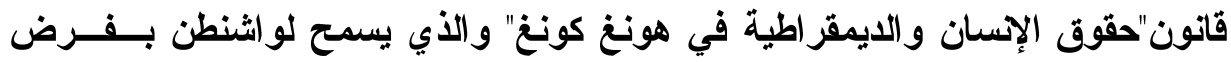
عقوبات على البر الرئيسي ومسؤولي هونج كونج لاتتهاكهم حقوق الإنسان وتقويضهم

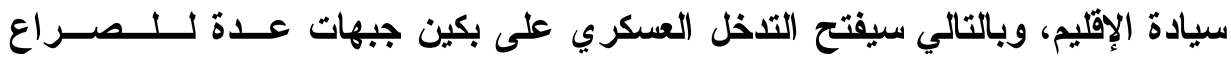
ستنتزف قوتها ومواردها الاقتصادية وتقوض من فكرة صعودها السلمي(ror). r يعتمد هذا السيناريو افتراض قبول حكومتي بكين وهونج كونج بشكل جزئي لمطالب المحتجين؛ فإلى جاتب قبولها بسحب مشروع القانون بشكل رسمي، ستلجأ الحكومتــان للتحايل على مطالب المحتجين من خلال الإعلان عن تشكيل لجنة للتحقيق في استخدام العنف خلال الاحتجاجات، كما يُعهر إليها تولى مسألة العفو والإفراج عن المعتقلـيـن

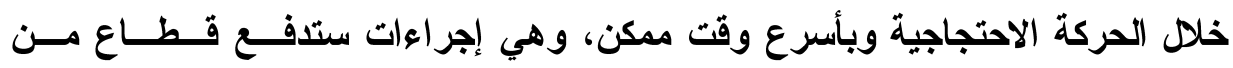
المحتجين مع مرور الوقت لإههاء حالة الاحتجاج، لاسيما أن الآثار السلبية على اقتصاد

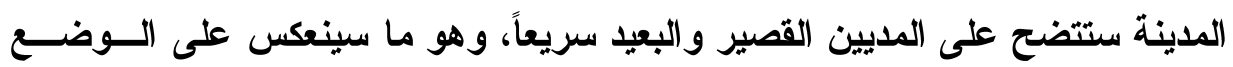
الاقتصاد للفرد ومستوى معيشته. ويُعد هذا السيناريو هو الأرجح؛ فمن خلاله ستتمكن بكين وحكومة هونج كونج من الحفاظ على صورتهما أمسام المجتمع الاولي، وستخلق الطريق أمام واشنطن لفتح أيــة جبهات تستنزف خلاهها بكين، كما أن مخرجات اللجنة المعنية ستوضع حجم الاخطــاء التي ارتكبها المحتجون وكذلك قوات الشرطة، ويمكن لحكومة هونج كونج الإعلان عن 
أن تلك الأخطاء تأتي في إطار الحفاظ على النظام العام والأمن والاستقر ار، وبالتــالــي نجاحها في التحايل على مطالب المحتجين والخروج من تلك الأزمة. الى جاتب هذين المشهدين الرئيسيين؛ ثمة احتمال كبير ان تستمر تلك الاحتجاجـات فترة اطول من الزمن، مما يجعل أحد المخارج الممكنة سلميا هو إجراء انتخابات عامة تحت إثر اف او رقابة دولية لضمان نزاهتها، وهو ما سيؤدى غالبا الى انتخاب عناصر مقبولة من سكان المدينة. خلاصة القول، تمر حكومة هونج كونج بأزمة سياسية و اقتصادية ربما ستكون من أكثر الأزمات خطورة على المدينة، وستستغرق وقتاً طويلاً لمعالجة آثارها وتـجـــاوز

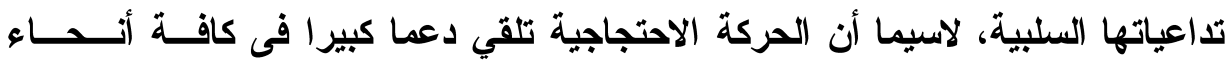
المدينة، ويتمتع ناشطوها بمرونة عالية في التعامل مع قوات الشرطة، ولايهم القـدرة على خلق ظهير دولي لها، مما يجعل خيارات إنهاءها محدودا، ويجبر بكين للبحث عن آليات عدة للتعامل مع مثل تلك الحركات الاحتجاجية والتخلي عن آلية القوة والعنف. 


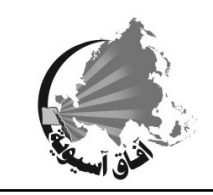

(1) Martin Purbrick," A Report of the 2019 HONG KONG protests", Journal of The Royal Central Asian Society,14 Oct 2019, Available at: https://doi.org/10.1080/03068374.2019.1672397

(2) Daniel Victor and Mike Ives," What's Happening With the Hong Kong Protests?", The New York Times, 31 October 2019, Available at:

https://www.nytimes.com/2019/10/15/world/asia/what-are-hong-kongprotests-about.html

(3) Martin Purbrick, Op. Cit.

(4) Ibid..

(5) John Feffer," Hong Kong and the Future of China", Foreign Policy In Focus, 11 September 2019, Available at: https://fpif.org/hong-kongand-the-future-of-china/

(6) Mary Hui," How Hong Kong went from the Umbrella Movement to a "revolution of our times"",Quartz, 27 Septemer 2019, Available at: https://qz.com/1710379/how-the-umbrella-movement-led-to-todayshong-kong-protests/

(7) Ibid..

(^) عنتر فرحات،"قانون تسليم المجرمين للصين يثير أزمة سياسية في هونج كونج"، المصـري

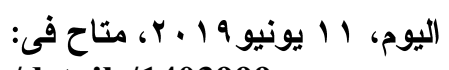

https://www.almasryalyoum.com/news/details/1403999

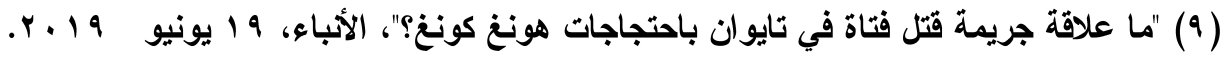

https://www.alanba.com.kw/BBCNews/1205

$$
\text { مناح فى: }
$$

(10) Martin Purbrick, Op. Cit.

(11) John Feffer, Op. Cit.

(12) Ibid.

( • (1) "ما علاقة جريمة قتل فتاة في تايوان باحتجاجات هونغ كونغ؟"، مرجع سبق ذكره.

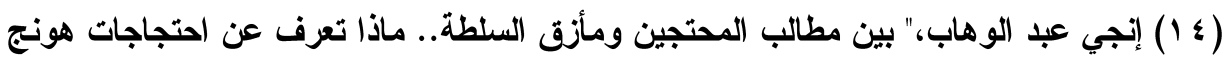

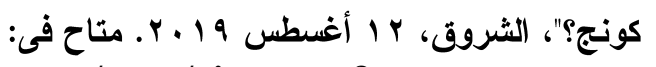

https://www.shorouknews.com/news/view.aspx?

cdate $=12082019 \& i d=a 0 a 32 f b 8-279 e-4 c e 7-80 c 1-f 16258407 d 5 b$

$$
\text { (0 1 ) عنتر فرحات، مرجع سبق ذكره. }
$$

(16) Martin Purbrick, Op. Cit.

(17) John Feffer, Op. Cit.

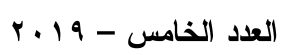




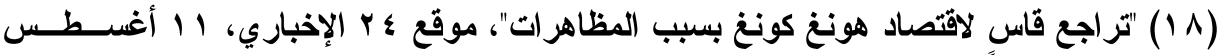

https://cutt.us/pbh52

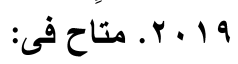

(19) Allen Morrison," How Hong Kong's protests are affecting its economy", The Conversation,22 August 2019, Available at:

https://theconversation.com/how-hong-kongs-protests-are-affectingits-economy-122098

(20) Sherisse Pham," Hong Kong is in a recession as five months of protests take a toll", CNN Business, 28 October 2019, Available at: https://edition.cnn.com/2019/10/28/economy/hong-kong-economy/ index.html

(21) Ibid..

(22) Eric Lam, Enda Curran, and Hannah Dormido," Hong Kong's Economy Is Failing. Here's How It Could Be Saved", Bloomberg, 16 October 2019, Available at:

https://www.bloomberg.com/news/articles/2019-10-16/hong-kong-seconomy-is-failing-here-s-how-it-could-be-saved

(23) Sherisse Pham, Op. Cit., p.

( ) إيمان فخري،" قوة المحتجين: سيناريوهات أزمة هونج كونج.. تلخل عسكري أم تـــازلات

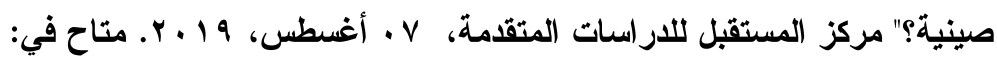
https://cutt.us/GIyvX

(25) John Feffer, Op. Cit, 